\section{Respuesta mundial al maltrato de las personas mayores en el contexto de la atención primaria ${ }^{1}$}

Palabras clave: maltrato al anciano, atención primaria de salud, Organización Mundial de la Salud.

\footnotetext{
1 Basado en: United Nations, Economic and Social Council. Abuse of older persons: recognizing and responding to abuse of older persons in a global context, report of the Secretary-General. New York: UN; 2002. Hallado en: www.un.org/ageing/ecn52002.pc2eng.pdf
}

Según estimaciones de las Naciones Unidas, para 2025 el número de personas de edad avanzada (es decir, de 60 años o más) ascenderá a 1,2 mil millones, equivalente al doble de la cifra actual de 600 millones. De cada millón de personas que cumple 60 años cada mes, $80 \%$ se encuentran en el mundo en desarrollo. A pesar de que en países desarrollados las personas de edad comprenden una fracción más grande de la población total que en países en desarrollo, en estos últimos, la población de personas mayores ha tenido un aumento porcentual mucho más acelerado. Además, el rápido envejecimiento de la población en dichos países se está produciendo en un contexto de acelerados cambios sociales (urbanización, mayor participación de las mujeres en la fuerza laboral, industrialización, etc.) y de pobreza generalizada. El maltrato de las personas de edad no es un fenómeno nuevo, pero la velocidad con la que envejece la población del mundo en este contexto de cambios sociales profundos llevará a su aumento inevitablemente.

El maltrato de las personas de edad avanzada puede ser físico, psicológico o emocional, sexual o económico. También puede obedecer a simple negligencia, intencionada o no. Como cualquier otra forma de maltrato, el de las personas de edad avanzada constituye una violación de los derechos humanos y es una causa importante de lesiones, enfermedad, pérdida de productividad, aislamiento y desesperación. Suele subnotificarse en todas las sociedades, en gran parte debido a que se ha estudiado muy poco. En lo que respecta al maltrato de las personas mayores, las sociedades están ahora donde estaban hace dos o tres decenios en relación con el abuso de los niños y la violencia contra la mujer. Todos eran fenómenos subnotificados $\mathrm{y}$ poco estudiados, $\mathrm{y}$, por consiguiente, atraían poca atención o incluso se consideraban inexistentes. Hoy en día hay cada vez más indicios de que el abuso de las personas mayores -incluido el fenómeno de la negligencia- es un problema social y sanitario de importancia, tanto en países prósperos como en países pobres, en países desarrollados como en países en desarrollo, en países del Norte como en países del Sur. Como tal, combatirlo implica una respuesta mundial concertada. Desde el punto de vista sanitario y social, el abuso de las personas de edad seguirá siendo un problema subnotificado y despertará poca atención, a no ser que los sectores de la atención primaria de salud (APS) y de los ser- 
vicios sociales estén preparados para identificar el problema y enfrentarlo.

La unidad de Envejecimiento y Ciclo de Vida de la Organización Mundial de la Salud (OMS) y el Centro de Gerontología Interdisciplinaria (CGI) de la Universidad de Ginebra, Suiza, están llevando a cabo un estudio que culminará en el desarrollo de una estrategia para prevenir el abuso de las personas de edad avanzada en el contexto de la APS. El actual proyecto de investigación tiene sus cimientos en un estudio multicéntrico internacional llevado a cabo por la OMS en colaboración con la Red Internacional de Prevención del Abuso y Maltrato en la Vejez (INPEA) y de HelpAge Internacional (HAI) en 2001-2002. En este estudio se investigaron, mediante grupos focales en ocho países, los puntos de vista y opiniones de personas mayores y de profesionales de la APS en torno al abuso de las personas de edad avanzada. De ahí salió una publicación titulada Missing voices: views of older persons on elder abuse (traducida al español con el título de Voces ausentes: visión de las personas mayores sobre el maltrato de las personas mayores) (1), que ha sido ampliamente difundida y presentada en numerosas conferencias internacionales. El proyecto actual toma en cuenta las recomendaciones explicitadas en Voces ausentes y sus actividades de seguimiento, actualmente en curso. Asimismo, se acoge a los principios y puntos de vista expresados en la Declaración de Toronto para la Prevención Global del
Maltrato de las Personas Mayores, de la OMS, que se lanzó en noviembre de 2002 en una conferencia celebrada en Ontario, Canadá.

En el actual estudio de la OMS y del CGI se hará una adaptación cultural y lingüística del Elder Abuse Suspicion Index (EASI), herramienta de tamizaje validada que se creó en Montreal, Canadá, en el Instituto René Bassin y en la Universidad de McGill. La finalidad es proporcionar información a los trabajadores de la APS de una manera que a la larga les permita detectar y combatir el maltrato de las personas mayores. Se organizarán grupos focales para poder determinar la aceptabilidad y utilidad del EASI entre personas de edad, trabajadores sociales y profesionales de la APS que desempeñan su labor en contextos culturales y geográficos fuera del Canadá, país donde se efectuó el estudio en un comienzo. Actualmente se cree que el estudio se efectuará en Chile, Costa Rica, España, Kenya, Singapur, Suiza y Túnez. De los resultados de este estudio cualitativo dependerá la puesta en marcha de un proyecto piloto en los respectivos países.

\section{REFERENCIAS}

1. Organización Mundial de la Salud. Voces ausentes: visión de las personas mayores sobre el maltrato de las personas mayores. [Missing voices: views of older persons on elder abuse]. Ginebra: OMS; 2002. 